\title{
THE ANALYSIS OF THE TRAFFIC SIGNS VISIBILITY DURING NIGHT DRIVING
}

\author{
Radovan Madleňák', Dominika Hoštáková1, Lucia Madleňáková1, Pawel Drozdziel², Adam Török ${ }^{3}$
}

1 University of Žilina, Faculty of Operation and Economics of Transport and Communications, Univerzitna 1, 010 26, Žilina, Slovakia, e-mail: radovan.madlenak@fpedas.uniza.sk, dominika.hostakova@fpedas.uniza.sk, lucia.madlenakova@fpedas.uniza.sk

2 Lublin University of Technology, Faculty of Mechanical Engineering, Nadbystrzycka 36, 20-618 Lublin, Poland, e-mail: p.drozdziel@pollub.pl

${ }^{3}$ Budapest University of Technology And Economics, Faculty of Transportation Engineering and Vehicle Engineering, 1111 Budapest, Múegyetem rkp.3. Hungary, e-mail: torok.adam@mail.bme.hu

Received: 2018.04 .25

Accepted: 2018.05.09

Published: 2018.06.01

\begin{abstract}
Road safety has an extremely important role in existing transportation systems. Drivers on the road are influenced by various factors (light and temperature conditions, visual smog, environment surrounding, etc.) and driver's distraction represents the most common cause of road traffic accidents. According our previous researches, we found that visual smog has a negative influence on drivers on the road. However, the task of placing the traffic signs on the roads is to increase road safety, thus positively influencing the driver while driving. The main objective of this article is to measure the visibility of traffic signs on selected roads in specific light conditions (in night). Secondary objective is to measure visibility of roadside advertisement (billboards) near roads that are influencing driver's distractions in negative way. The mobile ETG technology (eye tracking glasses) has been used as a method for measuring the gaze of the driver's eyes on traffic signs in night conditions. We compared the results from our previous research (daylight conditions) with the obtained results from the current research. On the basis of the comparison of both measurements we can find out differences (positive and negative) in influence of traffic signs and road side advertisements on drivers in various light conditions.
\end{abstract}

Keywords: eyetracking, traffic signs, driver, visibility, road safety.

\section{INTRODUCTION}

In recent years, scientific disciplines for measuring biometric data are coming more and more to the foreground, for which the term neuroscience is commonly used. Neuroscience is a natural science that examines the workings of the neural system of animals and humans, how it develops during life, and examines individual neurons, parts of the neural system, their connections, and methods of creating neural networks, their interaction and relation to the environment. Neuroscience also includes cognitive neuroscience that ex- amines what is happening in the human brain during cognitive processes. These processes include for example perception, thinking, remembering, recalling from memory, learning, etc. [2]. It searches for relationships between individual levels of the brain and tries to uncover causal laws, and it also tries to explain cognition, i.e. knowledge and learning about the world in humans and animals. There are several types of methods that can identify and evaluate changes in biometric data of test subjects. The most important include eye tracking ET, galvanic skin response GSR, electrocardiogram ECG, electroencephalogram 
Table 1. Overview of neuroscience methods used for biometric measurement

\begin{tabular}{|c|c|c|c|}
\hline Method & What is measured & How is it measured & Metrics \\
\hline $\begin{array}{c}\text { ET } \\
\text { (eye tracking) }\end{array}$ & $\begin{array}{c}\text { Corneal reflection and } \\
\text { pupil dilatation }\end{array}$ & $\begin{array}{c}\text { Infrared camera point } \\
\text { towards eyes }\end{array}$ & $\begin{array}{c}\text { Eye moments (gaze, fixations, sac- } \\
\text { cades), blinks, pupil dilatation }\end{array}$ \\
\hline $\begin{array}{c}\text { GSR } \\
\text { (galvanic skin response) }\end{array}$ & $\begin{array}{c}\text { Changes in skin } \\
\text { sweating }\end{array}$ & $\begin{array}{c}\text { Electrodes attached to } \\
\text { fingers, palms or soles }\end{array}$ & Skin conductance response (SCR) \\
\hline ECG & $\begin{array}{c}\text { Changes in electrical } \\
\text { activity caused by heart } \\
\text { contraction }\end{array}$ & $\begin{array}{c}\text { Electrodes attached to } \\
\text { chest or limbs }\end{array}$ & $\begin{array}{c}\text { Heart rate (HR, BPM), interbeat interval } \\
\text { (IBI), heart rate variability (HRV) }\end{array}$ \\
\hline EEG & $\begin{array}{c}\text { Changes in electrical } \\
\text { activity of the brain }\end{array}$ & $\begin{array}{c}\text { Electrodes places on } \\
\text { scalp }\end{array}$ & $\begin{array}{c}\text { Frequency band power (delta, theta, } \\
\text { alpha, beta gamma bands), frontal } \\
\text { laterization and asymmetry index event- } \\
\text { related potential, wavelets }\end{array}$ \\
\hline FEA & Activity of facial \\
(facial expression analysis) & $\begin{array}{c}\text { muscles and muscle } \\
\text { groups }\end{array}$ & $\begin{array}{c}\text { Webcam point towards } \\
\text { face along with computer } \\
\text { algorithms for feature } \\
\text { extraction }\end{array}$ & $\begin{array}{c}\text { Postion and orientation of head and } \\
\text { facial landmarks, activation of action } \\
\text { units (AUs) and emotion channels }\end{array}$ \\
\hline
\end{tabular}

EEG and facial expression analysis FEA [5]. The overview of options for each method is listed in the following Table 1.

We perceive approx. $90 \%$ of all information about the surrounding world through eyes. Therefore, in the viewpoint of neuroscience, the ET Eyetracking method is one of the most important methods of determining interaction between the environment and the human factor.

The science of eye tracking has been around as early as the 1800 s. Although the technology was not where it is today, people conducted eye movement studies for centuries using direct observations. In 1879, a French ophthalmologist named Louis Émile Javal made an observation when reading. He realized reading didn't involve smooth sweeping across the text, but rather the reader's eyes would have a series of short stops throughout with rapid eye movement [12]. These short stops are referred to as eye fixations. From the time, he made these observations and through the 1900 s, people continued to conduct eye tracking studies to make more sense of these eye fixations. Even today, people ask themselves why test subject's eyes stop on certain areas and why they fixate on certain areas more than others.

In the early 1900 s, an educational psychologist named Edmund Burke Huey built an early eye tracker. He used contact lenses with holes for the pupils. The contact lenses were connected to aluminum pointers, which would move along with the eyes to track a test subject's eye movement [13]. After Huey's early eye tracking technology, an experimental education psychologist named
Guy Thomas Buswell from Chicago built the first non-intrusive eye tracker [10]. Unlike Huey, Buswell used beams of light that were reflected on the test subject's eyes, and then recorded on film. It was still an early form of eye tracking technology, but again it was much less intrusive compared to Huey's eye tracking methods.

In the 1950s, a Russian psychologist named Alfred Lukyanovich Yarbus conducted several eye tracking studies that resulted in important eye tracking research. His research showed the relationship between eye fixations and the test subject's interest [9].

Moving into the 1970s, eye tracking studies and research continued to grow rapidly. Just like in the 1800s and early 1900s-1950s, the eye tracking research focused mainly on studying how people read. In the 1980s, Just and Carpenter came up with the Strong eye-mind hypothesis. This hypothesis states that when a subject is viewing a word or object, he or she is also processing it cognitively (thinking about it) for exactly the same amount of time he or she is fixating on it [1]. During this time, the Strong eye-mind hypothesis was questioned because of the idea of covert attention, which is the attention to something that one is not looking at.

The 1980s also saw the first use of eye tracking technology to help answer questions related to human-computer interaction [6]. Researchers analyzed how users navigated through and interacted with computer command windows [11]. These researchers also made advancements in the technology by using real time eye tracking results to help disabled people. 


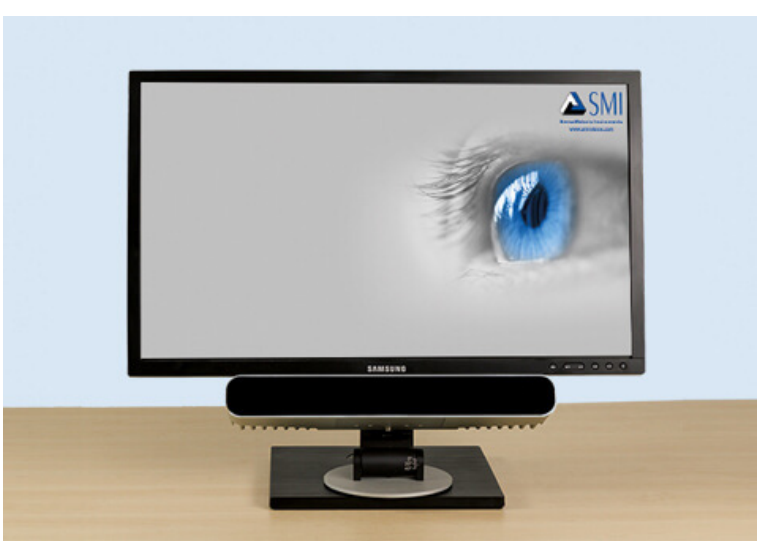

Fig. 1. Remote eye tracker SMI RED

There are two types of eye tracker: remote (also called screen-based or desktop) and headmounted (also called mobile) [2]. Remote eye trackers record eye movement at a distance, there is no attachments to respondent (tested subject). It is mounted below or placed close to a computer or screen and the respondent is is seated in front of the eye tracker (see Fig. 1). This type of eye tracker is recommended for observations of any screen-based stimulus material in laboratory settings such as pictures, videos and websites, offline stimuli (magazines, books etc.) and other small settings (small shelf studies etc.).

Head-mounted eye trackers record eye activity from a close range. It is mounted onto lightweight eyeglass frames and respondent is able to walk around freely (see Fig. 2). This equipment is recommended for observations of objects and task performance in any real-life or virtual environments (usability studies, product testing etc.).

The progressive and broadly applicable ET tool that is used in several research areas is the head-mounted eye tracker (eyetracking glasses). Eyetrack glasses now offer several options of use

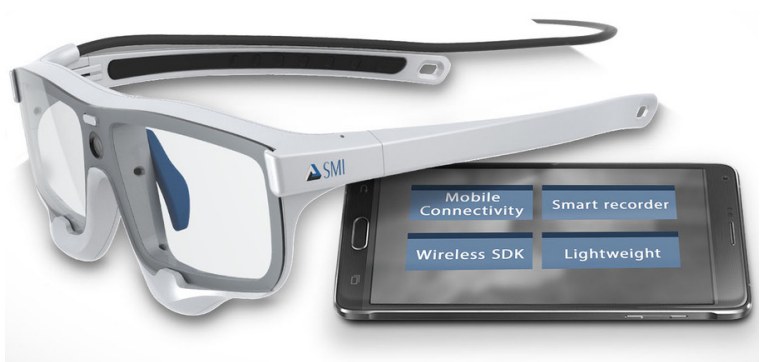

Fig. 2. Head-mounted eye tracker SMI ETG 2w

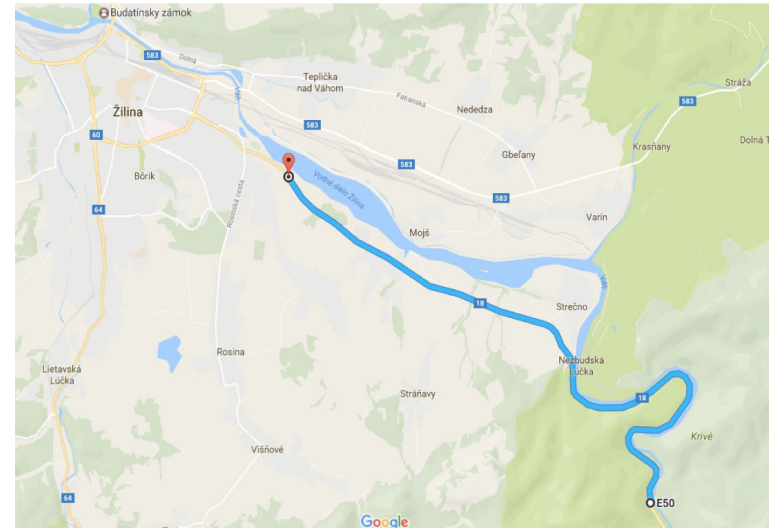

Fig. 3. Selected road section: Žilina (Šibenice) Strečno

in practice. The possibility of immediate movement in real life introduces unlimited number of research focused on the impact of sight. Tracking the impact of sight of the driver when driving a vehicle using eyetrack glasses is commonplace today $[3,8,14]$. They are used mainly in research focused on the impact of the environment (e.g. billboards) on the driver, but also on tracking time the driver spends on e.g. observing traffic signs when driving a vehicle $[4,7]$.

\section{ANALYSIS OF THE SITUATION}

The visibility of traffic signs has been realized on a $14 \mathrm{~km}$ road section located on the road between the towns of Žilina and Martin. Almost the entire section is outside of any town. Given it is a first-class road, the maximum permitted speed is 90 $\mathrm{km} / \mathrm{h}$., which is permitted on approx. $50 \%$ of the road. The road section is characterized by several speed restrictions and also narrowed down lanes in certain part of the road due to change in the number of lanes, specifically from two lanes to three lanes. Figure. 3 depicts the selected road section.

Table 2. Traffic accident statistics at selected road section (Žilina - Strečno) [5]

\begin{tabular}{|c|c|c|}
\hline & $\begin{array}{c}\text { 1.1.2016 - } \\
\text { 30.12.2016 }\end{array}$ & $\begin{array}{c}\text { 1.1.2015 - } \\
\mathbf{3 0 . 1 2 . 2 0 1 5}\end{array}$ \\
\hline $\begin{array}{c}\text { Number of traffic } \\
\text { accidents }\end{array}$ & 20 & 23 \\
\hline Number of fatalities & 4 & 4 \\
\hline $\begin{array}{c}\text { Number of serious } \\
\text { injuries }\end{array}$ & 3 & 14 \\
\hline Number of minor injuries & 6 & 13 \\
\hline Total material damage & $106300 €$ & $174220 €$ \\
\hline
\end{tabular}




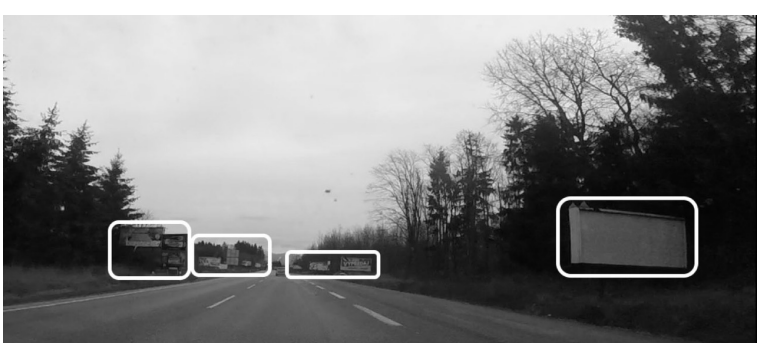

Fig. 4. Example of visual pollution on sellected road section

The Transport Inspectorate in Žilina provided traffic accident statistics on the selected road. Between 1. January 2016 and 30. December 2016, there were 20 traffic accidents in the road section no. 1, registered by the Transport Inspectorate in Žilina. The most common cause of the traffic accident was improper driving by the driver, which was recorded in 18 of the cases. A more detailed analysis of the traffic accidents is described in Table 2.

Based on the results of the analysis of visual smog done using a GoPro camera we found that there are a total of 174 billboards in the selected road section, which is 348 advertisement surfaces in both direction that can capture the driver's attention. Since the distance of the road section is $14 \mathrm{~km}$, it means that one billboard is placed every 80 meters. Majority of the billboards are 510 x 240 centimeters big and their average distance from the road is two meters (see Fig. 4).

\section{OBJECTIVE AND METHODOLOGY}

The main research goal was to identify the level of visibility of road signs in the selected road section under low light conditions, specifically at night. The analysis was conducted on a road near Žilina, which is characterized by a varied articulation and speed profile. The secondary research goal was to measure the effect of visual smog on the driver during driving under low light conditions. The results of the measurements were compared with the measurements conducted in the same section in the past. The following techniques and tools were used to achieve the goals:

- Statistics on traffic accidents on the selected road were obtained based on consultation with the county traffic engineer.

- Eyetrack glasses were used to collect data on driver's sight. These glasses from the SMI Company serve to capture and record the sight of a person in real time (see Fig 2).

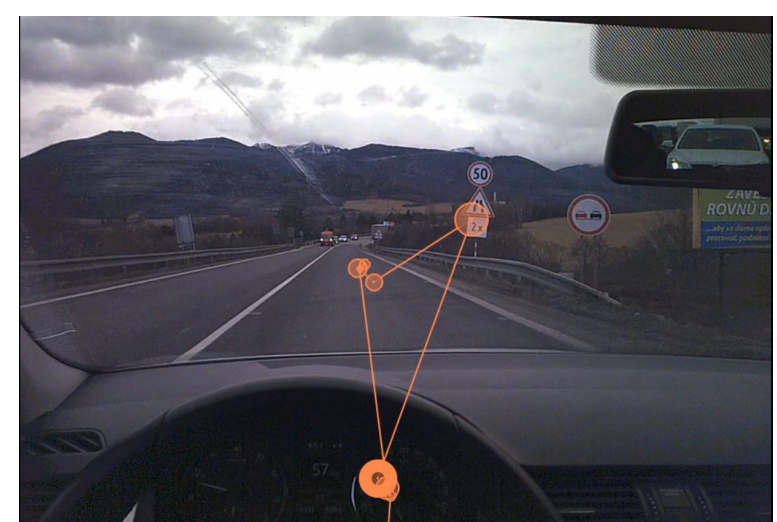

Fig. 5. Evaluation of driver eye movement in BeGaze software (fixations and saccedes)

- The BeGaze software was used in the final part to evaluate data collected using the Eyetrack glasses (see Fig. 5).

\section{RESULTS}

The main goal of the experiment was to assess the tracking of vertical traffic signs by the driving during driving in low light conditions (at night) and compare the data obtained with the data obtained during drive under optimum light conditions (during daylight). First part of experiment (night conditions) was realised during January 2017 and 5 test subjects participated. Second part of experimet (daylight conditions) was conducted on May 2017 and same test subjects participated on the experiment as in January. The results found during driving are listed in table 3. The table shows the average fixation times of drivers on advertising equipment and road signs in optimum and low light conditions.

During the whole drive under low light conditions, the tested subjects looked at on average 32 road signs out of a total of 150 . This means that the driver saw in night $21.3 \%$ of road signs, i.e. on average every fifth road sign (see Fig. 6).

Table 3. Comparison of driver's gaze fixation depending on light conditions

\begin{tabular}{|c|c|c|}
\hline & $\begin{array}{c}\text { Optimum light } \\
\text { conditions }\end{array}$ & $\begin{array}{c}\text { Low light } \\
\text { conditions }\end{array}$ \\
\hline $\begin{array}{c}\text { Number of gaze fixation } \\
\text { on traffic signs }\end{array}$ & 52 & 32 \\
\hline $\begin{array}{c}\text { Number of gaze fixation } \\
\text { on billboards }\end{array}$ & 82 & 15 \\
\hline $\begin{array}{c}\text { Time of longest fixation } \\
\text { on the billboard }\end{array}$ & $2,2 \mathrm{~s}$. & $0,8 \mathrm{~s}$. \\
\hline
\end{tabular}




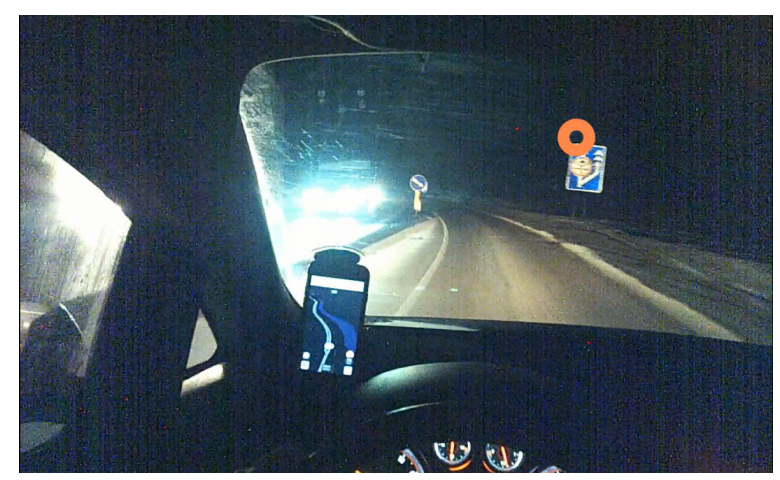

Fig. 6. Driver's view at vertical traffic sign during night driving

Compared with driving during the day, the drivers focused their attention on 52 road signs, which is $34.6 \%$ of all road signs (see Fig. 7). The value of tracking road signs (sight fixed on them) during the night drive is $38.5 \%$ lower than tracking road signs by the driver under good light conditions. This is interesting despite the fact that the majority of road signs contain reflective elements. Based on analyzing the eyetrack camera videos this can be explained by the driver being blinding by the incoming cars, which caused his sight to be higher (outside of road signs) compared to testing under good light conditions.

The secondary goal of testing was to measure the effect of visual smog on the driver under low light conditions. The goal of this measurement was to determine, whether the driver focuses his sight on ads also under low light conditions. The measurement took place on the same road between Žilina and Martin, where there are 174 billboards, with more than $97 \%$ of them or not illuminated billboards.

The results of the measurement shown that the time the driver spent on observing visual

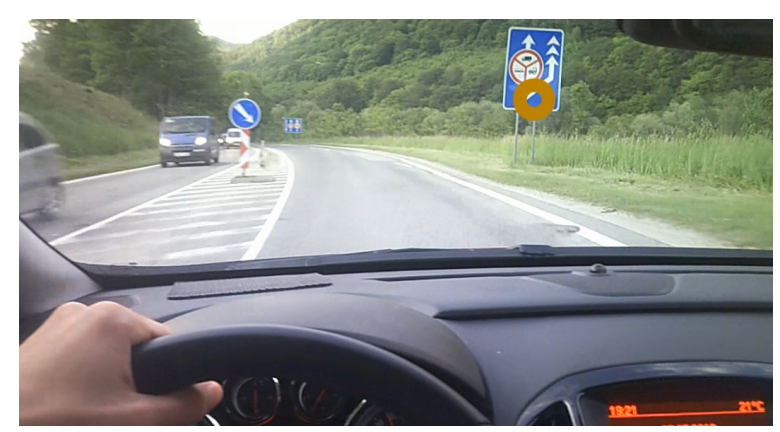

Fig. 7. Driver's view at vertical traffic sign during daylight driving smog in night, compared to the average time the driver spent watching billboards during the day under good light conditions, is more than five times lower. In absolute terms this means that the driver looked only on 15 billboards during the whole drive. The duration of fixation on a billboard was short, usually lasting less than $0.5 \mathrm{~s}$, which amounts to a total of approx. 7.5 seconds.

The driver paid the most attention to billboards with a reflective element. Compared to classic billboards these were more prominent and the driver noticed them from a greater distance. Equally, the duration of fixation of the driver's sight was longer in this case than with non-illuminated billboards without a reflective element.

\section{CONCLUSIONS}

Roads signs on roads have a key role in ensuring road safety. Their visibility to drivers during the drive is the main prerequisite in preventing the occurrence of non-standard situations and limiting the likelihood of traffic accidents. Therefore, we set to identify how the visibility of vertical road signs changes depending on the light conditions. Based on experimental testing using an eyetracking camera in real conditions of a selected road we came to the conclusion that under low light conditions (night driving) the number of fixations on traffic signs was 38.5\% lower than when driving in good light conditions. This result was all the more interesting, because road signs are equipped with reflective elements that should ensure the same visibility during the night, as well as during the day. By testing we found out that the level of fixation on road signs is lowered by the intensity of road traffic (especially by dazzling the driver by the opposite car).

In the secondary measurement, we focused on the visibility of negative elements found around the road (visual smog). The number of fixations of sight on billboards in the measured section during the day was higher than the number of fixations on road sighs, but the change of light conditions decreased the number of fixations on visual smog by $81.7 \%$. This decrease is the consequence of absence of reflective elements on billboards.

Finally, it can be concluded that by comparing the results from the experimental measurements carried out under good light conditions (during the day) and under low light conditions (at night) there is significant reduction of road signs visibility during driving. 


\section{ACKNOWLEDGEMENT}

This article was undertaken as part of research project: 1/0721/15 VEGA Research, on the impact of postal services and telecommunication convergence on regulatory approaches in the postal sector.

\section{REFERENCES}

1. Embretson, S. E.: A cognitive design system approach to generating valid tests: Application to abstract reasoning. Psychological Methods, 1998, 3(3), 380-396. doi:10.1037/1082-989x.3.3.380.

2. Fabus, Ju, Nemcek, B., Kremenova, I., Fabus, Jo.: Usability of eyetrack technology for educational institutions. Paper presented at the 7th International Technology, Education and Development Conference (INTED), Valencia, 2013.

3. Hudak, M., Madlenak, R.: The Research of Driver Distraction by Visual Smog on Selected Road Stretch in Slovakia, Procedia Engineering, 2017, Vol. 178, 472-479.

4. Hudak, M., Madlenak, R.: The Research of Driver's Gaze at the Traffic Signs. In: Hajek, P., Sahota, T. \& Jones, M. A. (Eds.) CBU INTERNATIONAL CONFERENCE PROCEEDINGS 2016: INNOVATIONS IN SCIENCE AND EDUCATION. (2016), pp. 896-899, CBU Prague, Czech republic, (2016).

5. Hudak, M.: Economic impacts of visual smog in transport [Thesis], Tutor: Madlenak, R., 2017, University of Zilina, FPEDAS, p. 104.
6. Jarasuniene, A., Yatskiv, I.: Analysis of improvement of road safety using intelligent transport systems (ITS). TRANSPORT MEANS 2007, Proceedings, Kaunas, Kaunas University of Technology, pp.182-185, 2007.

7. Kolarovszki P., Tengler J., Majercakova M.: The new model of customer segmentation in postal enterprises. Procedia Engineering, 2016, vol. 230, pp. 121-127.

8. Madlenak, R., Hudak, M.: The Research of Visual Pollution of Road Infrastructure in Slovakia. In: Challenge of Transport Telematics, TST 2016, Springer Int Publishing Ag, 2016, vol.640, pp. 415-425.

9. Martinez-Conde, S., Macknik, S. L.: From Exploration to Fixation: An Integrative View of Yarbus's Vision. Perception, 2015, 44(8-9), pp. 884-899. doi:10.1177/0301006615594963.

10. Robertson, J. M.: Guy Thomas Buswell (18911994) - Obituary. American Psychologist, 1996, 51(2), pp. 152-152.

11. Torok, A.: Comparative analysis between the theories of road transport and emission. Transport 32(2), 192-197 (2017).

12. Wade, N. J., Tatler, B. W.: Did Javal measure eye movements during reading? Journal of Eye Movement Research, 2009, 2(5), p.7.

13. Walczyk, J. J., Tcholakian, T., Igou, F., Dixon, A. P.: One Hundred Years of Reading Research: Successes and Missteps of Edmund Burke Huey and Other Pioneers. Reading Psychology, 2014, 35(7), pp.601-621.

14. Young, M.S., Mahfoud, J.M.: Driven to Distraction: Determining the effects of Roadside Advertising on Driver Attention. Brunel University; London, England. (2007). 